\title{
Vacuolated Lymphocyte Count
}

National Cancer Institute

\section{Source}

National Cancer Institute. Vacuolated Lymphocyte Count. NCI Thesaurus. Code

C111329.

The determination of the amount of vacuolated lymphocytes present in a sample. 